\title{
Dynamic expression of FKBP5 in the medial prefrontal cortex regulates resiliency to conditioned fear
}

\author{
Marangelie Criado-Marrero, ${ }^{1}$ Roberto J. Morales Silva, ${ }^{2}$ Bethzaly Velazquez, ${ }^{1}$ \\ Anixa Hernández, ${ }^{1}$ María Colon, ${ }^{1}$ Emmanuel Cruz, ${ }^{1}$ Omar Soler-Cedeño, ${ }^{1}$ and \\ James T. Porter ${ }^{1}$ \\ ${ }^{1}$ Department of Basic Sciences, Ponce Research Institute, Ponce Health Sciences University, Ponce 00732, Puerto Rico; \\ ${ }^{2}$ Department of Biology, University of Puerto Rico-Ponce, Ponce 00734, Puerto Rico
}

\begin{abstract}
The factors influencing resiliency to the development of post-traumatic stress disorder (PTSD) remain to be elucidated. Clinical studies associate PTSD with polymorphisms of the FK506 binding protein 5 (FKBP5). However, it is unclear whether changes in FKBP5 expression alone could produce resiliency or susceptibility to PTSD-like symptoms. In this study, we used rats as an animal model to examine whether FKBP5 in the infralimbic (IL) or prelimbic (PL) medial prefrontal cortex regulates fear conditioning or extinction. First, we examined FKBP5 expression in IL and PL during fear conditioning or extinction. In contrast to the stable expression of FKBP5 seen in PL, FKBP5 expression in IL increased after fear conditioning and remained elevated even after extinction suggesting that IL FKBP5 levels may modulate fear conditioning or extinction. Consistent with this possibility, reducing basal FKBP5 expression via local infusion of FKBP5-shRNA into IL reduced fear conditioning. Furthermore, reducing IL FKBP5, after consolidation of the fear memory, enhanced extinction memory indicating that IL FKBP5 opposed formation of the extinction memory. Our findings demonstrate that lowering FKBP5 expression in IL is sufficient to both reduce fear acquisition and enhance extinction, and suggest that lower expression of FKBP5 in the ventral medial prefrontal cortex could contribute to resiliency to PTSD.
\end{abstract}

Fear is an adaptive response for coping with dangerous situations that involves a physiological stress reaction and the secretion of glucocorticoids to promote adaptive learning processes. Maladaptation to this response can promote the development of stress disorders such as post-traumatic stress disorder (PTSD) (Wessa and Flor 2007; Yehuda and LeDoux 2007; Morrison and Ressler 2014). Patients with PTSD often exhibit disrupted hypothalamic-pituitary-adrenal (HPA) axis responses (van Zuiden et al. 2013; Morrison and Ressler 2014). Stressful events activate the HPA axis causing the release of glucocorticoids such as cortisol (humans) or corticosterone (rodents) from the adrenal glands (Vedeckis et al. 1989; Raubenheimer et al. 2006; Spijker and van Rossum 2012). Multiple proteins regulate the interactions of circulating glucocorticoids with their cytoplasmic glucocorticoid receptors (GR) including FK506 binding protein 4 (FKBP4) and FK506 binding protein 5 (FKBP5). FKBP4 increases the affinity of GR for glucocorticoids, while FKBP5 serves as a negative intracellular regulator of GR signaling that binds to GR and decreases its affinity for glucocorticoids and impedes GR nuclear translocation (Davies et al. 2002; Tatro et al. 2009; Cioffi et al. 2011).

Clinical studies have found associations between FKBP5 polymorphisms and altered GR sensitivity, low cortisol levels, risk of PTSD development, and treatment efficacy (Binder 2009; Koenen and Uddin 2010; Xie et al. 2010; Boscarino et al. 2011; Mehta 2011; van Zuiden et al. 2012; McKlveen et al. 2013). This implies that malfunction of the FKBP5 protein could lead to a maladaptive stress response that predisposes people to develop PTSD after trauma exposure. However, whether simply changing FKBP5 expression is sufficient to induce PTSD-like symptoms has not been examined. In rodents, chronic corticosterone and early postnatal stress exposure impair fear extinction (Gourley et al. 2009;

\section{Corresponding author: jporter@psm.edu}

Article is online at http://www.learnmem.org/cgi/doi/10.1101//m.043000.116.
Matsumoto et al. 2009) pointing to HPA axis dysfunction as a potential cause of the impaired fear extinction seen in patients with PTSD (Wessa and Flor 2007; Milad et al. 2009; Hariri and Holmes 2015). In addition to impairing extinction, chronic corticosterone or dexamethasone (GR agonist) exposure reduces methylation of the FKBP5 gene leading to up-regulation of FKBP5 mRNA in the prefrontal cortex (Scharf et al. 2011; Ewald et al. 2014). Therefore, changes in FKBP5 in the medial prefrontal cortex (mPFC) could contribute to the development of PTSD-like behaviors. In this study, we focused on the infralimbic (IL) and the prelimbic cortexes (PL) since these regions of the mPFC play a prominent role in the control of fear conditioning and extinction (Milad and Quirk 2002, 2012; Sierra-Mercado et al. 2011; Giustino and Maren 2015). We combined behavioral and molecular approaches to address the following questions: (1) Is FKBP5 expression in IL and PL altered by fear conditioning or extinction? (2) Is modulation of FKBP5 expression in IL or PL sufficient to affect fear conditioning and/or extinction memory?

\section{Results}

Fear conditioning and extinction alter FKBP5 expression in IL but not PL

Since previous studies have suggested different roles of IL and PL during fear modulation, we began by examining FKBP5 baseline expression at the mRNA and protein level. Figure $1 \mathrm{~A}, \mathrm{~B}$ shows the freezing behavior and the different time points that brain

(C) 2017 Criado-Marrero et al. This article is distributed exclusively by Cold Spring Harbor Laboratory Press for the first 12 months after the full-issue publication date (see http://learnmem.cshlp.org/site/misc/terms.xhtml). After 12 months, it is available under a Creative Commons License (AttributionNonCommercial 4.0 International), as described at http://creativecommons. org/licenses/by-nc/4.0/. 
A

\begin{tabular}{|l|l|l|l|}
\hline Group & \multicolumn{1}{|c|}{ Day 1 } & \multicolumn{1}{c|}{ Day 2 } & Day 3 \\
\hline Naïve & $\begin{array}{l}4 \text { tones, sacrificed } \\
\text { 5hrs later }\end{array}$ & & \\
\hline COND & $\begin{array}{l}1 \text { hab + 3 tone-shock } \\
\text { pairings then } \\
\text { sacrificed } 5 \text { hrs later }\end{array}$ & & \\
\hline COND24 & $\begin{array}{l}1 \text { hab }+3 \text { tone-shock } \\
\text { pairings }\end{array}$ & Sacrificed & \\
\hline EXT & $\begin{array}{l}1 \text { hab }+3 \text { tone-shock } \\
\text { pairings }\end{array}$ & $\begin{array}{l}15 \text { tones, } \\
\text { sacrificed } \\
5 \text { hrs later }\end{array}$ & \\
\hline EXT 24 & $\begin{array}{l}1 \text { hab + 3 tone-shock } \\
\text { pairings }\end{array}$ & 15 tones & Sacrificed \\
or RT-PCR
\end{tabular}

B

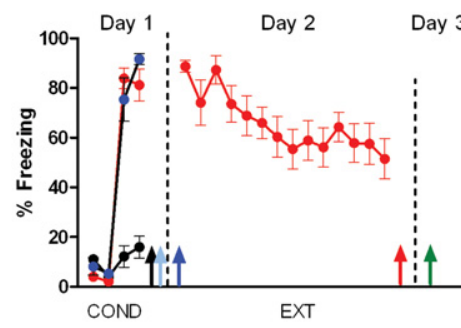

C

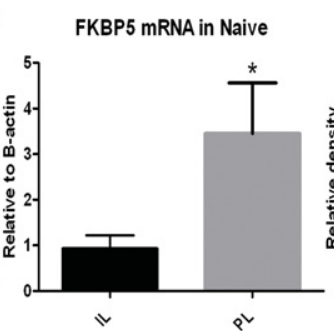

D

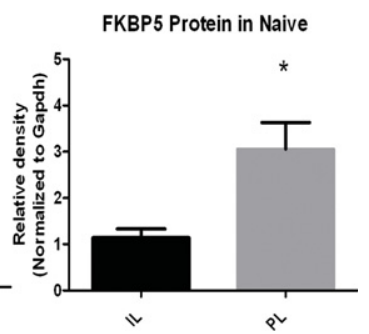

Figure 1. Different FKBP5 levels in IL and PL of naïve rats. $(A)$ Behavioral protocol and sacrifice time points for mRNA and protein extraction. (B) Expression of fear during behavioral training in all groups. Tissue punches were extracted at the time of sacrifice indicated by the arrows and RT-PCR and Western blots were used to detect FKBP5 expression. (C) FKBP5 mRNA expression in IL and PL in naïve rats normalized to B-actin. (D) FKBP5 protein relative to GAPDH is also higher in PL than in IL. Unpaired $t$-test $\left(^{*}\right)$ $P<0.01, n=7-10$ rats in each group.

tissue was extracted to measure RNA and protein expression. Figure 1C,D shows that FKBP5 mRNA $\left(t_{(15)}=2.74, P=0.01\right)$ and protein levels $\left(t_{(13)}=3.01, P=0.01\right)$ in naïve rats were significantly higher in PL than IL.

Next we examined whether FKBP5 mRNA expression in IL or PL changes after fear conditioning or extinction $5 \mathrm{~h}$ after learning (when memory is being consolidated) or $24 \mathrm{~h}$ after learning (when memory is already consolidated). We chose to quantify FKBP5 expression at $5 \mathrm{~h}$ after training because FKBP5 mRNA is increased between 2 and $8 \mathrm{~h}$ after stress exposure (Scharf et al. 2011). In Figure 2A, groups of rats were exposed to tones-only (naïve), fear conditioning (COND) alone, or fear conditioning and extinction (EXT). The naïve group was sacrificed $5 \mathrm{~h}$ later. The COND group was sacrificed $5 \mathrm{~h}$ after fear conditioning, while the COND24 group was sacrificed $24 \mathrm{~h}$ after conditioning (before EXT) to determine baseline levels before extinction. Similarly the EXT and EXT24 groups were sacrificed 5 and $24 \mathrm{~h}$ after fear extinction, respectively.

After fear training, corticosterone levels should be elevated so we expected more activation of GR and increased FKBP5 in the COND group. As predicted, FKBP5 was significantly elevated $5 \mathrm{~h}$ after fear conditioning and remained elevated the next day, $\left(F_{(4,30)}=24.16, P<0.0001\right)$. Tukey's post hoc test confirmed a significant increase in FKBP5 mRNA 5 (COND) and 24 (COND24) hours after conditioning compared with naïve $(P<0.05)$. Since rats must recall the fear memory at the beginning of extinction, we would expect an increase in FKBP5 mRNA in EXT group that would be less than the increase after COND. Consistent with this idea, we found a transient decrease in FKBP5 mRNA in IL 5 $\mathrm{h}$ after extinction that reversed to COND24 levels the following

day. In contrast to the changes in IL, the mRNA expression of FKBP5 in PL did not vary across learning phases $\left(F_{(3,23)}=0.71, P=0.55\right.$; Fig. $\left.2 \mathrm{~B}\right)$ suggesting that FKBP5 expression in IL is more critical for regulating GR signaling during fear learning. Since we did not observe changes in PL $5 \mathrm{~h}$ after extinction, we did not look for changes in FKBP5 mRNA $24 \mathrm{~h}$ after extinction in this brain region.

Similar to FKBP5 mRNA, IL FKBP5 protein levels varied after fear conditioning and extinction (Fig. 2C,D). FKBP5 protein increased in IL $24 \mathrm{~h}$ after fear conditioning. One-way ANOVA revealed a significant effect of group $\left(F_{(4,36)}=\right.$ 5.23, $P<0.001)$. Tukey's post hoc test confirmed that FKBP5 protein increased $24 \mathrm{~h}$ after fear conditioning in IL compared with naïve and COND groups $(P<0.01)$. In contrast to FKBP5 mRNA, FKBP5 protein remained elevated 5 and $24 \mathrm{~h}$ after extinction compared with COND $(P<0.05)$. As with the FKBP5 mRNA, the FKBP5 protein did not change in PL $\left(F_{(4,28)}=0.67, P=0.62\right.$; Fig. $\left.2 \mathrm{E}, \mathrm{F}\right)$.

Since the release of corticosterone in response to the stress of fear conditioning can increase FKBP5 expression, we next examined whether the association of the tone and shock contributed to the increase in FKBP5 protein after fear conditioning. Animals received either fear conditioning (COND 24; one tone followed by three tones paired with a shock) or unpaired tones and shocks (Unpaired 24; four tones with a 2-min inter-trial interval and three consecutive shocks immediately before removing from the conditioning chamber). As shown in Figure 3A, the COND 24 group learned to fear the tone while the Unpaired 24 group did not. In response to the final tone, the COND 24 group froze more than the Unpaired 24 group $\left(t_{(20)}=14.08, P<0.001\right)$. The following day both groups were sacrificed and FKBP5 protein expression was compared in IL and PL tissue punches by Western blot (Fig. $3 B, C)$. The COND 24 group expressed more FKBP5 in IL than the Unpaired 24 group $\left(t_{(20)}=2.35, P<0.029\right)$. Consistent with our above findings, FKBP5 expression in PL was similar in both groups $\left(t_{(20)}=1.51, P=0.15\right)$. These findings suggest that associative fear learning increases FKBP5 expression in IL.

\section{Decreasing FKBP5 in IL reduces acquisition of conditioned fear}

The dynamic changes in IL FKBP5 expression after fear conditioning and extinction suggest that IL FKBP5 expression might modulate fear conditioning or extinction. To test this possibility, we determined whether reducing FKBP5 expression in IL is sufficient to alter fear conditioning or extinction. First, we verified that shRNA against FKBP5 would knockdown the expression of FKBP5 in IL. After infusing rats with FKBP5-shRNA or scrambleshRNA plasmids, we confirmed cannula placement (Fig. 4A), and verified GFP expression in transfected IL neurons (Fig. 4B). In a separate group, we collected IL tissue punches from FKBP5-shRNA or scramble-shRNA-infused rats and measured FKBP5 protein levels (Fig. 4C,D). FKBP5 protein was significantly reduced 2 and $5 \mathrm{~d}$ after 
A

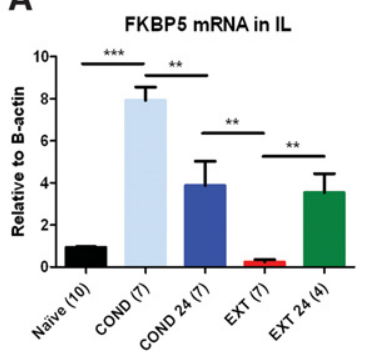

C

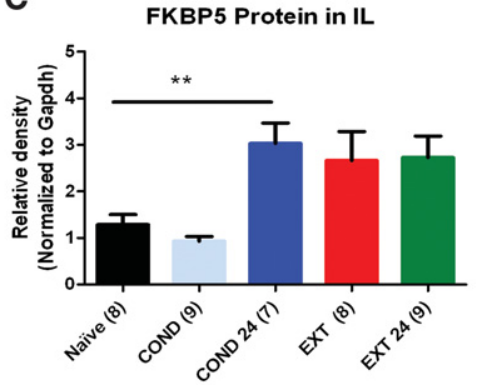

E

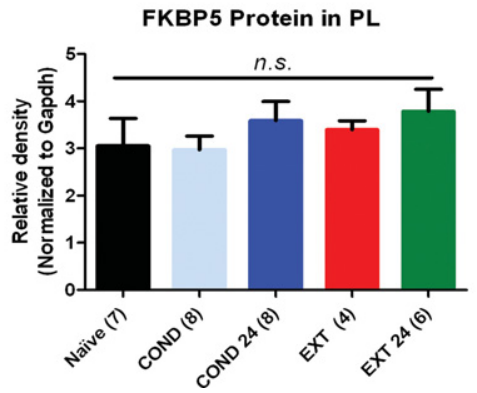

B

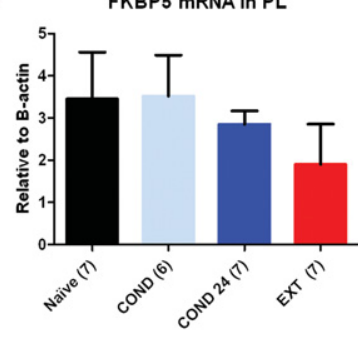

D

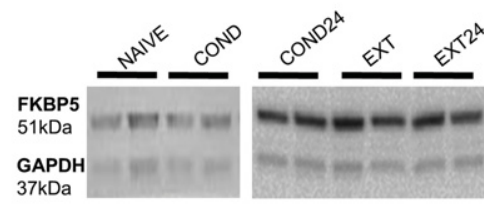

$\mathbf{F}$

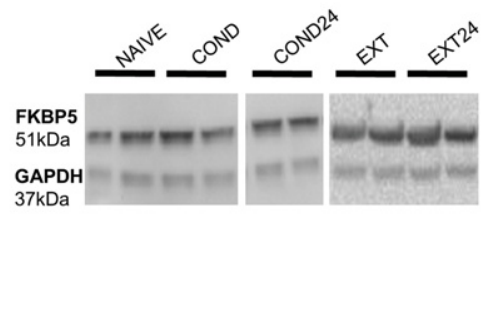

Figure 2. Fear conditioning and extinction alter FKBP5 mRNA and protein expression in IL. (A) FKBP5 mRNA expression from IL tissue punches extracted after behavioral training and normalized to B-actin. (B) FKBP5 mRNA expression in PL was also analyzed and compared with IL tissue punches. (C-F) FKBP5 protein expression in IL and PL tissue punches normalized to GAPDH and representative Western blots. $\left.{ }^{* * *}\right) P<0.001,\left({ }^{* *}\right) P<0.01$.

infusion $\left(F_{(2,9)}=14.52, P=0.002\right)$. Tukey post hoc test confirmed that there was less FKBP5 protein $5 \mathrm{~d}$ after infusion than $2 \mathrm{~d}$ after infusion $(P<0.01)$. As the greater reduction was observed $5 \mathrm{~d}$ after infusion, all the behavioral testing was done $5 \mathrm{~d}$ after plasmid infusion.

We subsequently examined whether reducing the expression of FKBP5 in IL would have an effect on fear conditioning using either scramble-shRNA or FKBP5shRNA plasmid to down-regulate FKBP5 expression in IL prior to fear conditioning (Fig. 5A). Only those rats with confirmed infusion in IL were included in the analysis (Fig. 5B). Infusion of the FKBP5shRNA did not affect freezing to the first conditioning tone $\left(t_{(21)}=1.26, \quad P=\right.$ $0.23)$ or to the context before the first tone was presented (pretone, $t_{(21)}=$ $0.43, P=0.68)$ indicating that reducing IL FKBP5 did not affect basal freezing to the context or the tone. However, infusion of the FKBP5-shRNA plasmid into
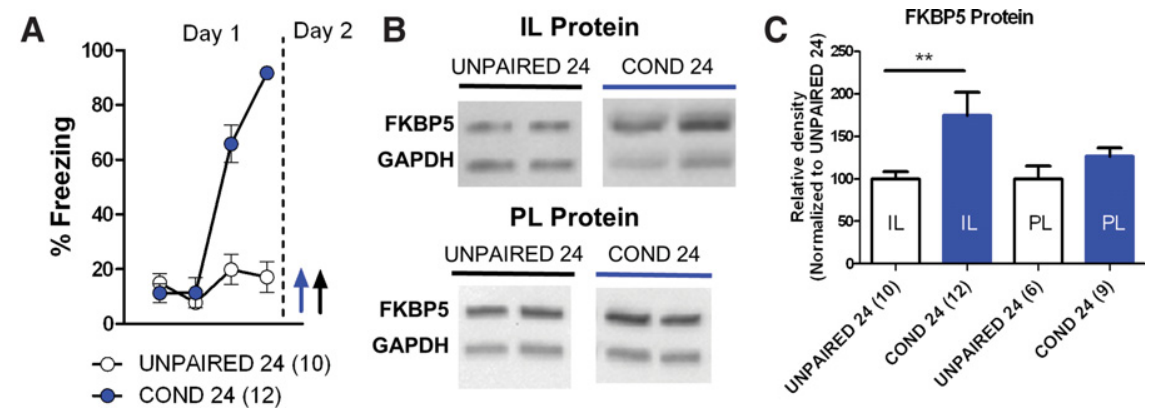

Figure 3. Aversive associative learning increases IL expression of FKBP5 protein. (A) Behavior of groups that received paired (COND24) or unpaired (Unpaired24) tones and shocks. Animals were sacrificed the next day as indicated by arrows. (B) Western blots of FKBP5 protein in IL tissue punches relative to GAPDH. (C) FKBP5 protein expression in IL and PL tissue punches normalized to unpaired group from each structure. $\left(^{* *}\right) P<0.01$. 
A

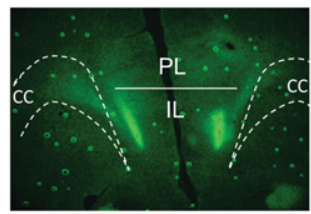

B

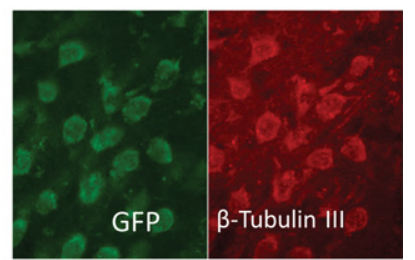

C

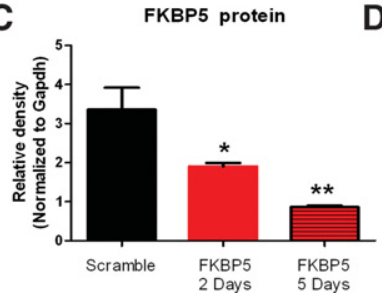

Figure 4. Knockdown of FKBP5 protein with FKBP5-shRNA plasmid infusions. (A) Localized expression of GFP in IL $5 \mathrm{~d}$ after bilateral infusion of Fkbp5-shRNA plasmid. (B) Expression of GFP from Fkbp5-shRNA plasmid in IL neurons. (C) FKBP5 protein from IL tissue punches extracted 2 or $5 \mathrm{~d}$ after infusion of Fkbp5-shRNA plasmids normalized to GAPDH. (D) Western blot showing reduced expression of FKBP5 in IL tissue punches from rats $5 \mathrm{~d}$ after infusion of scramble or Fkbp5-shRNA plasmids. $\left(^{*}\right)$ $P<0.05,(* *) P<0.01, n=4-5$ rats in each group. (CC) corpus callosum.

exposing the rats to extinction (Fig. 6A-C). A repeated-measures ANOVA showed that both groups showed similar fear acquisition $\left(F_{(1,20)}=0.02, P=0.89\right)$, fear recall $\left(F_{(1,20)}=1.1, P=0.31\right)$, and extinction learning $\left(F_{(1,20)}=0.68, P=0.42\right)$. Since both groups showed similar levels of fear recall at the beginning of extinction, the FKBP5-shRNA did not cause a nonspecific degradation of the fear memory. However, rats infused with FKBP5-shRNA into IL exhibited less fear during extinction recall (Fig. 6D; unpaired $t$-test, $t_{(20)}=2.28, P=0.03$ ) indicating that reducing FKBP5 enhanced extinction memory. Taken together our results indicate that FKBP5 levels in IL play a major role in regulating fear conditioning (Fig. 5C) and extinction recall (Fig. 6D).

\section{Reduction of FKBP5 in PL does not affect fear response}

To exclude the possibility that the reduction in fear acquisition observed in FKBP5-shRNA-infused rats was due from backflow of plasmids from IL to PL, we infused the FKBP5-shRNA and scrambleshRNA plasmids into PL prior to fear conditioning. Cannula placement and GFP expression are shown in Figure 7A,B. Although PL modulates fear expression (Vidal-Gonzalez et al. 2006; Choi et al. 2010; Milad and Quirk 2012), reducing FKBP5 in PL did not affect fear conditioning (Fig. 7C; $F_{(2,19)}=0.50, P=0.61$ ) or extinction recall (Fig. $7 \mathrm{D} ; t_{(20)}=0.91$, $P=0.37)$ indicating that the effects of FKBP5-shRNA infusions into IL were not due to effects in PL.

\section{Discussion}

Although data suggest that FKBP5 plays a role in PTSD, there is no evidence of a
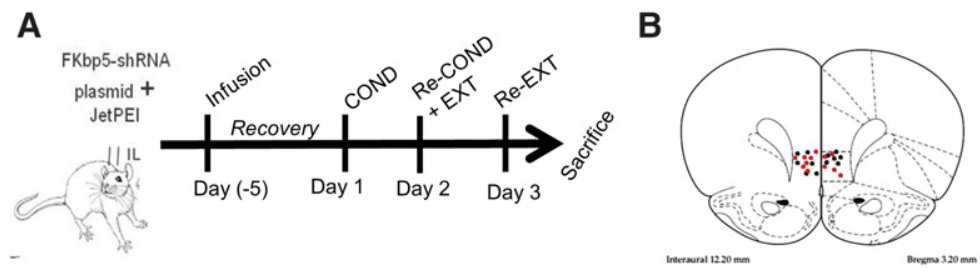

causal relationship between FKBP5 expression and PTSD-like behavior. In this study, we examined whether FKBP5 expression in the mPFC affects fear conditioning or extinction. We found that FKBP5 protein expression is elevated in IL, but not PL, after fear conditioning and extinction. Furthermore, the expression of FKBP5 in IL has functional consequences, since reducing basal FKBP5 expression in IL reduced fear acquisition and facilitated extinction recall. Similarly, decreasing the expression of IL FKBP5 after fear conditioning enhanced extinction recall without affecting extinction learning. Conversely, reducing FKBP5 in PL did not affect fear acquisition or extinction. Our findings provide evidence for a causal link between IL FKBP5 expression and conditioned fear levels and suggest that lower FKBP5 expression in the ventral medial prefrontal cortex (human equivalent of IL) may increase resiliency to the development of PTSD after a traumatic event. Our findings provide a possible explanation for why FKBP5 polymorphisms associated with lower FKBP5 protein expression seem to favor less risk of PTSD (Binder et al. 2004, 2008).

A previous study showed that FKBP5 mRNA basal levels are not uniform among brain structures and regions with lower basal expression exhibited larger increases in FKBP5 mRNA in response to stress or GR agonists (Scharf et al. 2011). Consistent with this, we found that IL expressed lower baseline levels of FKBP5 and showed larger increases in FKBP5 mRNA after fear conditioning than PL. The differential expression of FKBP5 in IL and PL could be related to the distinct roles of GR signaling in these structures (McKlveen et al. 2013). GR signaling in PL modulates basal corticosterone levels, while GR activity in IL seems to mediate stress adaptation (McKlveen et al. 2013). Higher levels of FKBP5 in PL might maintain a stable lower GR activity to prevent PL from responding to every stressful event to allow more stable basal corticosterone levels.

In addition, IL and PL FKBP5 expression were differentially affected by fear conditioning and extinction. Consistent with stress-induced release of corticosterone, FKBP5 mRNA and subsequently protein increased in IL after fear conditioning. Although the FKBP5 mRNA in IL decreased after extinction, the FKBP5 protein remained elevated. It is possible that the FKBP5 protein may

\section{C}

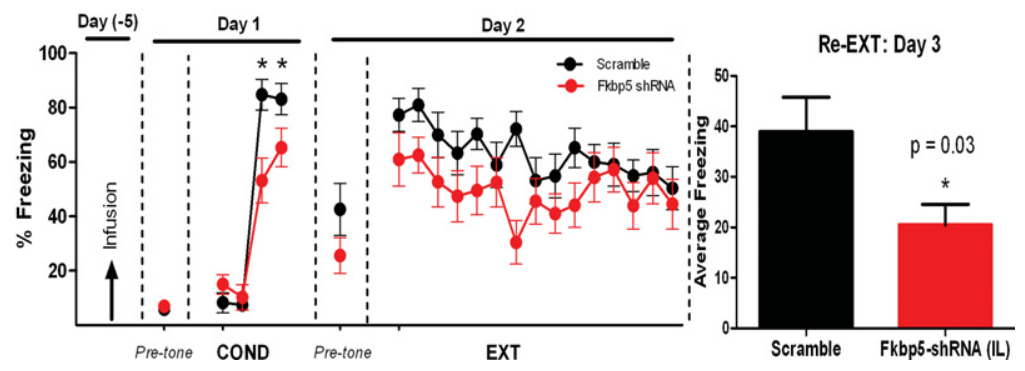

Figure 5. Knockdown of FKBP5 in IL prior to conditioning reduces fear learning. ( $A$ ) Timeline for behavioral training after IL infusion of Fkbp5-shRNA or control (scramble) plasmids $5 \mathrm{~d}$ prior to COND. (B) Cannula placement for scramble (black dots) and Fkbp5-shRNA (red dots) rats. (C) Freezing of rats infused with Fkbp5-shRNA or scramble plasmid into IL. $n=11-12$ for each group, $(*) P<0.05$; \# $P=0.09$. 
Table 1. FKBP5 reduction in IL does not influence locomotion or anxiety-like behaviors

\begin{tabular}{lccc}
\hline Behavioral test & Scramble & FKBP5-shRNA & P value \\
\hline Open field & & & \\
$\quad$ Distance (cm) & $339 \pm 52$ & $287 \pm 67$ & 0.54 \\
Mean speed (cm/s) & $1.13 \pm 0.17$ & $0.95 \pm 0.22$ & 0.55 \\
$\quad$ Center time (s) & $15 \pm 5$ & $17 \pm 9$ & 0.82 \\
Zero maze & $20 \pm 2$ & $18 \pm 2$ & 0.57 \\
$\quad$ Open arms \# entries & $150 \pm 15$ & $161 \pm 14$ & 0.61 \\
Open arms time (s) & $21 \pm 2$ & $18 \pm 2$ & 0.44 \\
Closed arms \# entries & $149 \pm 15$ & $137 \pm 13$ & 0.55 \\
Closed arms time (s) & & & \\
\hline
\end{tabular}

Values are listed as the mean \pm the standard error of the mean.

have decreased at a later time point: however, even $24 \mathrm{~h}$ after fear extinction IL FKBP5 remained elevated. A previous clinical study of FKBP5 polymorphisms also found a disconnect between FKBP5 protein and mRNA levels (Binder et al. 2004) suggesting that FKBP5 mRNA may not accurately reflect FKBP5 protein levels. In contrast to the dynamic regulation of FKBP5 in IL during fear conditioning and extinction, PL levels of FKBP5 did not change suggesting that FKBP5 expression in the two structures are regulated by different mechanisms.

Furthermore, IL expression of FKBP5 modulates fear learning and memory as knocking down the basal levels of FKBP5 in IL reduced fear learning. This finding is surprising, since IL is not proposed to play a role in fear learning in current models (Giustino and Maren 2015). However, fear conditioning does increases cfos in IL (Morrow et al. 1999) indicating that IL is activated by fear learning. Since stimulation of IL suppresses fear expression (Milad and Quirk 2002; Mueller et al. 2008; Santini and Porter 2010) we propose that reducing FKBP5 expression enhances IL activity to impair fear learning perhaps by modulating plasticity in the amygdala (Quirk et al. 2003; Berretta et al. 2005; Herry et al. 2008; Amano et al. 2010; Ciocchi et al. 2010; Li et al. 2011; Cho et al. 2013). Both intrinsic excitability and synaptic plasticity in IL neurons are associated with suppressed fear expression (Quirk and Mueller 2008; Santini et al. 2008; Pattwell et al. 2012; SepulvedaOrengo et al. 2013) and could account for the weaker fear conditioning after reducing FKBP5, since glucocorticoids can enhance intrinsic and synaptic excitability of neurons (Duvarci and Paré 2007; Rosenkranz et al. 2010; Revest et al. 2014).

It is also possible that decreasing FKBP5 could reduce fear acquisition by augmenting brain-derived neurotrophic factor (BDNF) levels in IL, since BDNF activity is increased by glucocorticoids (Gourley et al. 2009; Revest et al. 2014) and infusions of BDNF into IL reduce fear recall (Peters et al. 2010). However, BDNF infusion into IL has no effect on fear acquisition (Peters et al. 2010) suggesting that the impairments in fear acquisition are not due high levels of BDNF in IL.

In addition to modulating fear conditioning, reducing FKBP5 in IL also en- hanced extinction recall. Previous studies demonstrate that reducing IL activity during extinction learning disrupts extinction recall (Santini and Porter 2010; Sierra-Mercado et al. 2011), whereas, increasing IL activity enhances extinction recall (Vidal-Gonzalez et al. 2006; Santini and Porter 2010; CriadoMarrero et al. 2014). Therefore, reducing FKBP5 may have facilitated intrinsic (Santini et al. 2008) or synaptic plasticity (Pattwell et al. 2012; Sepulveda-Orengo et al. 2013) in IL by modulating SK- or M-type potassium channels (Santini and Porter 2010; Santini et al. 2012; Criado-Marrero et al. 2014), $\beta$-adrenergic receptors (Mueller et al. 2008), metabotropic glutamate receptor type 5 (mGluR5) receptors (Fontanez-Nuin et al. 2011), NMDA receptors (Burgos-Robles et al. 2007), BDNF (Peters et al. 2010), muscarinic receptors (Santini et al. 2012), or ERK (Kim et al. 2011; Gupta et al. 2013), all of which regulate extinction recall via local effects in IL.

An alternative mechanism by which reducing FKBP5 in IL might affect fear conditioning and extinction is by modulating the release of corticosterone in response to fear conditioning and fear retrieval. Reducing GR expression in IL increases the release of corticosterone in response to acute stress (McKlveen et al. 2013). Therefore, reducing FKBP5 in IL may enhance GR signaling leading to lower corticosterone levels which would impair consolidation of the fear memory (Raio and Phelps 2015; Rimmele et al. 2015). Since the reconsolidation of the fear memory is also dependent on GR signaling (Jin et al. 2007), the enhanced extinction recall could be mediated in part by impaired fear memory reconsolidation. In addition, the selective reduction in FKBP5 in IL would likely compensate for lower corticosterone levels and permit GR-mediated consolidation of the extinction memory in IL.

Regardless of the mechanism, our findings highlight the importance of FKBP5 levels in IL for the regulation of fear acquisition and extinction. Reducing basal FKBP5 levels selectively in IL

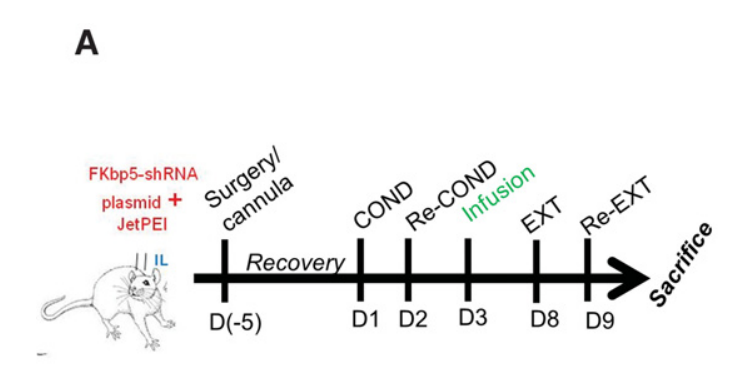

C

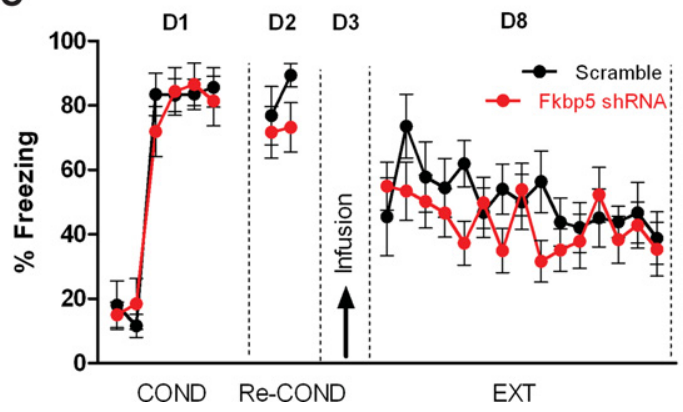

D
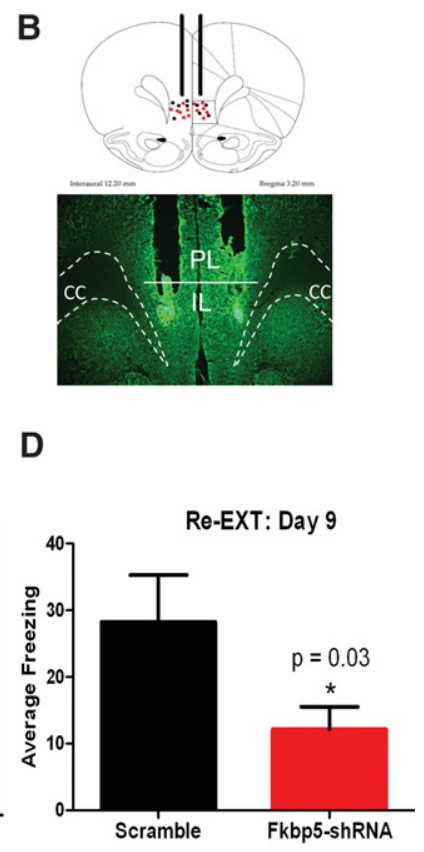

Figure 6. Reducing IL FKBP5 after fear conditioning facilitates extinction recall. $(A)$ Timeline for behavioral training after IL infusion of Fkbp5-shRNA or control (scramble) plasmids $5 \mathrm{~d}$ prior to EXT. (B) IL cannula placement for scramble (black dots) and Fkbp5-shRNA (red dots) rats and GFP expression. (C) Freezing of rats infused with Fkbp5-shRNA or scramble plasmid into IL prior extinction. (D) Average freezing of IL-infused rats to two recall tones on day $9 . n=9-13$ for each group, $\left(^{*}\right) P<0.05$. 
A

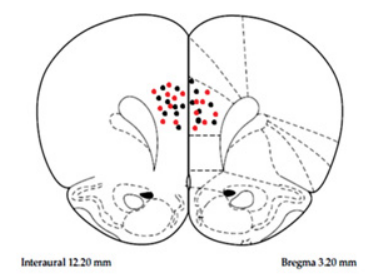

B

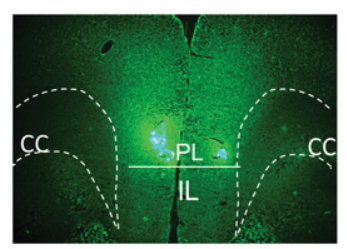

D
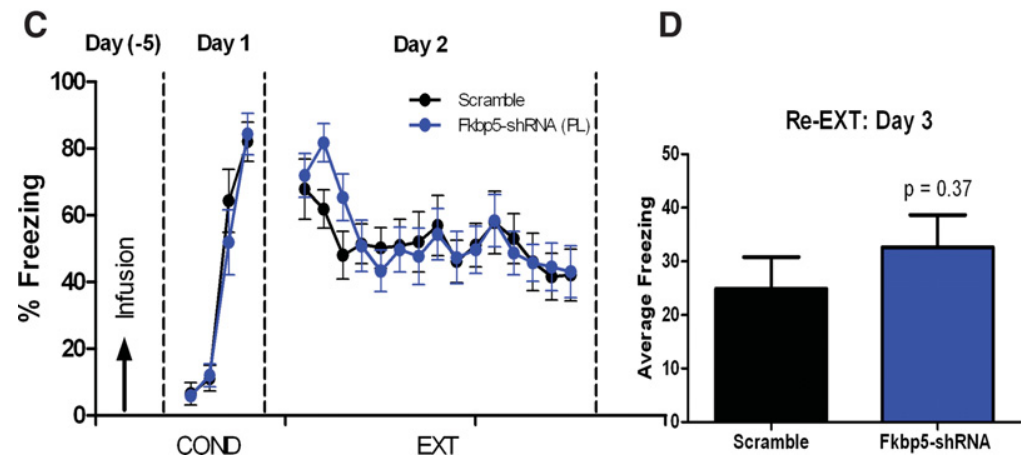

Figure 7. Reducing FKBP5 in PL does not affect fear conditioning or extinction. ( $A$ ) Cannula placement for scramble (black dots) and Fkbp5-shRNA (red dots) rats. (B) Localized expression of GFP in PL $5 \mathrm{~d}$ after bilateral infusion of Fkbp5-shRNA plasmid. (C) Freezing of rats infused with Fkbp5shRNA or scramble plasmid into PL. $(D)$ Average freezing of PL-infused rats to two recall tones on day 3 . $n=10-12$ for each group, unpaired $t$-test $P>0.05$.

was sufficient to decrease the sensitivity to fear acquisition. This implies that people with lower FKBP5 expression in the vmPFC may be more resilient to developing excessive fear following a traumatic event. In addition, after a traumatic event, therapies to reduce FKBP5 expression in IL might facilitate extinction. For example, dexamethasone was recently shown to reduce FKBP5 mRNA in the amygdala and enhance fear extinction (Sawamura et al. 2015). FKBP5 inhibitors, such as SAFit2 (Hartmann et al. 2015), are being developed and could prove to be useful for facilitating exposure therapy in patients with PTSD.

\section{Materials and Methods}

\section{Animal subjects}

Adult male Sprague-Dawley rats (60 d post-natal) were obtained from the Ponce Health Sciences University colony and pairhoused in clear polyethylene cages. Rats were maintained on a 12-h light-dark cycle, in a temperature-controlled room, with food and water available. All animal work was approved by the Ponce Health Sciences University Institutional Animal Care and Use Committee (IACUC), and carried out in accordance with the NIH Guide for the Care and Use of Laboratory Animals.

\section{FKBP5 $m$ RNA and protein expression}

Fear conditioning and extinction protocols were performed in the same context as previously described (Sepulveda-Orengo et al. 2013). The conditioned stimulus was a tone (amplitude: $80 \mathrm{~dB}$; frequency: $4 \mathrm{kHz}$; duration: $30 \mathrm{sec}$; inter-trial interval: $2 \mathrm{~min}$ ). This tone was paired with the unconditioned stimulus which was an electric shock $(0.44 \mathrm{~mA}, 0.5 \mathrm{sec})$ delivered through the chamber floor bars during the conditioning phase. Only the groups infused prior to extinction received $0.50 \mathrm{~mA}$ shocks with five tone-shocks pairing during fear conditioning to strengthen the fear memory because of the $7 \mathrm{~d}$ gap between fear conditioning and extinction. The chamber was cleaned with $70 \%$ ethanol between each session. Each rat's behavior was monitored and record- ed using digital video cameras (Micro Video Products). The fear response was quantified as the time spent not moving during the CS (time spent freezing).

To examine changes in FKBP5 mRNA and protein expression, adult rats were exposed to fear conditioning, extinction, and extinction recall. During fear conditioning (day 1), rats received one habituation tone and three paired tone-shock trials at 2-min inter-trial intervals. The next day (day 2), rats received 15 tone-alone trials for extinction training. Twenty-four hours later (day 3), rats were exposed to two tones to test for fear extinction recall. Rats were sacrificed at 5 or $24 \mathrm{~h}$ after each phase of training to determine mRNA and protein expression. For comparison, a naïve group received four tone-alone trials (naïve) and was sacrificed $5 \mathrm{~h}$ later. In a separate experiment, we compared an unpaired control group (unpaired 24) to a fear conditioned group (COND 24) to exclude the possibility that changes in FKBP5 were entirely due to stress and not the associative fear learning. The Unpaired 24 group received four tones with a $2 \mathrm{~min}$ inter-trial interval and at the end of the session 3 consecutive shocks immediately before removing from the conditioning chamber. Twenty-four hours later both groups were sacrificed and FKBP5 protein expression was compared by Western blot.

\section{RNA analysis}

After sacrifice, brain tissue punches were extracted from IL and PL to measure FKBP5 mRNA expression. Samples were transferred in Qiazol Buffer (QIAGEN, 79306) following RNA extraction. RNA was extracted using the miRNeasy Micro Kit (QIAGEN, 217084). Total RNA $(0.5 \mu \mathrm{g})$ was processed in duplicate for complementary DNA synthesis using the iScript cDNA synthesis kit (Bio-Rad, 170-8890) and iQ SYBR Green Supermix (Bio-Rad, 170-8880). Cycle threshold values $(C t)$ were detected and normalized relative to $\mathrm{B}$-actin. We analyzed gene expression using the Eppendorf RealPlex2 PCR machine. Primers for FKBP5 and $\mathrm{B}$-actin were purchased from SA Biosciences: PPR51629B-FKBP5; PPR06570C-Rat B-actin (FKBP5, 96 bp, Ref. position 1222, NM_001012174).

\section{Protein analysis}

From different groups of rats, $1-\mathrm{mm}$ brain tissue punches of IL and PL slices were taken and homogenized in erythrocyte lysis buffer (ELB) containing protease and phosphatase inhibitors (Sigma-Aldrich, P2714 and P5726). Protein was quantified using a BCA assay (Thermo Scientific, 23225). Protein $(15 \mu \mathrm{g})$ was loaded into a gel and run at $100 \mathrm{~V}$ for $60-75 \mathrm{~min}$. Then, the SDS-PAGE gel was transferred onto a PVDF membrane using the iBlot (Life Technologies, IB1001). Membranes were incubated in blocking solution ( $25 \mathrm{~g}$ of non-fat milk, $50 \mathrm{~mL}$ of $10 \times$ PBS, $500 \mu \mathrm{L}$ of Tween-20) for $1 \mathrm{~h}$, followed by overnight incubation with rabbit polyclonal FKBP5 (Abcam, ab2901, 1:1000) and GAPDH (SCB, Fl-335- 25778) antibodies. Membranes were washed and then incubated with a secondary antibody (GE, NA934) for $1 \mathrm{~h}$. Membranes were washed and incubated for 5 min with SuperSignal West Pico Chemiluminescent Substrate (Thermo Scientific, 34080) and the band intensities were measured using Bio-Rad ChemiDoc XRS Imaging System and Image J software. 


\section{shRNA plasmids}

A set of four SureSilencing FKBP5-shRNA plasmids containing GFP were used to knockdown the expression of the FKBP5 gene by targeting different sites of its mRNA (SA Biosciences KR51629, Clone 1, cgaaccaatgagctta; Clone 2, gcgaggatctatttgaagatt; Clone 3, cgccaacatgttcaagaagtt; Clone 4, cgtgattcagtacgggaagat). A scramble-shRNA (ggaatctcattcgatgcatac) was used as a negative control. Competent $E$. coli were transformed with SureSilencing shRNA plasmids and plasmids were purified using the EndoFree Plasmid Maxi Kit (QIAGEN, 12362).

\section{Preconditioning shRNA infusions into IL}

Animals (285-310 g) were subcutaneously injected with the analgesic carprofren $(5 \mathrm{mg} / \mathrm{kg})$ and anesthetized with isoflurane (3\%$4 \%$ ). Using a stereotaxic apparatus, a bilateral guide cannula (26-gauge stainless steel) was implanted into IL and infused with FKBP5-shRNA or scramble plasmid. To enhance transfection efficiency, the in vivo jetPEI (Polyplus, 201-10G) transfection reagent was infused together with a $0.5 \mu \mathrm{g}$ of the plasmid clones at $0.5 \mu \mathrm{L} / \mathrm{min}$ (Hassani et al. 2005). To reduce tissue damage, cannulas were removed after the shRNA infusion and the holes were sealed with wax to reduce plasmid backflow. Infusions were aimed at IL (+2.5 $\mathrm{mm} \mathrm{AP,} 0 \mathrm{~mm}$ ML to bregma, and $-4.4 \mathrm{~mm}$ DV to skull surface) or PL (AP, $+2.5 \mathrm{~mm}$; ML $0 \mathrm{~mm} ; \mathrm{DV},-3.4 \mathrm{~mm}$ ). After waiting $5 \mathrm{~d}$ for plasmid expression, rats were exposed to fear conditioning (one habituation tone and three paired tone-shock trials at 2-min inter-trial intervals) on day 1 and two recall tones on day 2.

Different groups were exposed to open-field and elevated zero maze (EZM) testing $5 \mathrm{~d}$ after infusing the rats with Fkbp5shRNA or scramble plasmids into IL. For the open-field test, we placed the rats in a $45 \mathrm{~cm} \times 45 \mathrm{~cm} \times 40 \mathrm{~cm}$ wood box covered with black acrylic under low illumination. Rats were allowed to explore the arena for $5 \mathrm{~min}$ and distance traveled, mean speed, and time spent in the center were measured. One hour after exposing the rats to the open-field test, rats were individually placed in the EZM (SD Instruments) which is covered with black acrylic (11 $\mathrm{cm} \times 72 \mathrm{~cm}$; diameter $120 \mathrm{~cm}$ ) and has two open quadrants and two closed quadrants. For a total of 5 min we measured the number of entries into and the time spent in both closed and open quadrants. The maze was cleaned between each run with $70 \%$ ethanol.

\section{Preextinction shRNA infusions}

To allow infusion of the shRNA plasmids after fear conditioning, dual cannulas were anchored with stainless steel screws and secured to the skull surface with dental cement during stereotaxic surgery. Five days later, rats received one habituation tone and five tone-shock pairings at 2-min inter-trial intervals to strengthen the fear memory because of the 7-d gap between fear conditioning and extinction. On day 2 , rats received two tone-alone trials to ensure adequate recall of conditioning. On day 3 , the shRNA or scramble plasmids were infused with in vivo jetPEI. Five days later rats received extinction (15 tone-alone trials) and extinction recall (two tone-alone trials) the following day.

\section{Preconditioning shRNA infusions into PL}

FKBP5-shRNA or scramble plasmids were infused into PL during surgery as described for preconditioning infusions into IL. Five days later rats received fear conditioning (one habituation tone and three paired tone-shock trials at 2-min inter-trial intervals). The next day, rats received extinction (15 tone-alone trials). The following day, rats received two tones to test for extinction recall.

\section{Immunofluorescence}

After behavioral training, rats infused with the shRNA plasmids were euthanized with pentobarbital $(150 \mathrm{mg} / \mathrm{kg})$ and perfused with $0.9 \%$ saline followed by $30 \%$ sucrose-formalin solution. Brains were submerged in $30 \%$ sucrose/formalin solution before embedding in paraffin. Coronal slices $(4 \mu \mathrm{m})$ were washed with xylene $(15 \mathrm{~min})$ and dehydrated in ethanol washes. Sections were rinsed in 10\% PBS (Sigma-Aldrich, P3813) and heated in citrate-EDTA Buffer ( $\mathrm{pH} \mathrm{6.0)}$ at $95^{\circ} \mathrm{C}$ for $40 \mathrm{~min}$. After cooling, brain sections were incubated with protein blocking solution (15 min) (BioGenex, HK112-9KE); then incubated overnight at $4^{\circ} \mathrm{C}$ with primary antibodies against tubulin $\beta$ III [TU-20] (Abcam, ab7751; 1:50) and GFP (Abcam, ab6556; 1:2000). The tissue was washed with 10\% PBS (Sigma-Aldrich, P3813) and incubated for $1 \mathrm{~h}$ with the following secondary antibodies from Life Technologies: Alexa Fluor 555 goat anti-mouse (A-21422, 1:100) and Alexa Fluor 488 goat Anti-rabbit (A-11034, 1:50,000). Images were taken using an Olympus BX60 light microscope and analyzed using the NIS Elements Imaging Software (Nikon).

\section{Statistical analysis}

Using FreezeScan software, the percent of time spent freezing (cessation of movements) during each 30-sec tone was measured and analyzed. The ANY Maze software (SD Instruments) was used to quantify the Open-field and Zero Maze tests. Student's $t$-test or one-way and repeated-measures ANOVA (Prism Software and SPSS) were used to analyze the mRNA, protein, and behavioral data. Following a significant main effect with one-way ANOVA, post hoc tests were performed with Tukey HSD tests or Independent sample $t$-tests.

\section{Competing interest statement}

The authors declare no biomedical financial interests or potential conflicts of interest.

\section{Acknowledgments}

We thank Dr. Richard J. Noel and Dr. Vanessa Rivera-Amil for their comments on the manuscript. Also, we thank Dr. Annelyn Torres-Reveron for her support with the statistical analysis. This work was supported by the RCMI BRAIN and MAGIC Cores (NIMHHD G12 MD007579-27), the PSM and UPR-Ponce RISE Programs (R25 GM082406, R25 GM096955) and R15 MH101700 from the National Institutes of Health.

\section{References}

Amano T, Unal CT, Paré D. 2010. Synaptic correlates of fear extinction in the amygdala. Nat Neurosci 13: 489-494.

Berretta S, Pantazopoulos H, Caldera M, Pantazopoulos P, Pare D. 2005 Infralimbic cortex activation increases c-fos expression in intercalated neurons of the amygdala. Neuroscience 132: 943-953.

Binder EB. 2009. The role of FKBP5, a co-chaperone of the glucocorticoid receptor in the pathogenesis and therapy of affective and anxiety disorders. Psychoneuroendocrinology 34(Suppl 1): S186-S195.

Binder EB, Salyakina D, Lichtner P, Wochnik GM, Ising M, Pütz B, Papiol S, Seaman S, Lucae S, Kohli MA, et al. 2004. Polymorphisms in FKBP5 are associated with increased recurrence of depressive episodes and rapid response to antidepressant treatment. Nat Genet 36: 1319-1325.

Binder EB, Bradley RG, Liu W, Epstein MP, Deveau TC, Mercer KB, Tang Y, Gillespie CF, Heim CM, Nemeroff CB, et al. 2008. Association of FKBP5 polymorphisms and childhood abuse with risk of posttraumatic stress disorder symptoms in adults. JAMA 299: 1291-1305.

Boscarino JA, Erlich PM, Hoffman SN, Rukstalis M, Stewart WF. 2011. Association of FKBP5, COMT and CHRNA5 polymorphisms with PTSD among outpatients at risk for PTSD. Psychiatry Res 188: 173-174.

Burgos-Robles A, Vidal-Gonzalez I, Santini E, Quirk GJ. 2007. Consolidation of fear extinction requires NMDA receptor-dependent bursting in the ventromedial prefrontal cortex. Neuron 53: 871-880.

Cho JH, Deisseroth K, Bolshakov VY. 2013. Synaptic encoding of fear extinction in mPFC-amygdala circuits. Neuron 80: 1491-1507.

Choi DC, Maguschak KA, Ye K, Jang S-W, Myers KM, Ressler KJ. 2010. Prelimbic cortical BDNF is required for memory of learned fear but not extinction or innate fear. Proc Natl Acad Sci 107: 2675-2680.

Ciocchi S, Herry C, Grenier F, Wolff SBE, Letzkus JJ, Vlachos I, Ehrlich I, Sprengel R, Deisseroth K, Stadler MB, et al. 2010. Encoding of conditioned fear in central amygdala inhibitory circuits. Nature 468: $277-282$ 
Cioffi DL, Hubler TR, Scammell JG. 2011. Organization and function of the FKBP52 and FKBP51 genes. Curr Opin Pharmacol 11: 308-313.

Criado-Marrero M, Santini E, Porter JT. 2014. Modulating fear extinction memory by manipulating SK potassium channels in the infralimbic cortex. Front Behav Neurosci 8: 96.

Davies TH, Ning Y-M, Sanchez ER. 2002. A new first step in activation of steroid receptors: hormone-induced switching of FKBP51 and FKBP52 immunophilins. J Biol Chem 277: 4597-4600.

Duvarci S, Paré D. 2007. Glucocorticoids enhance the excitability of principal basolateral amygdala neurons. J Neurosci 27: 4482-4491.

Ewald ER, Wand GS, Seifuddin F, Yang X, Tamashiro KL, Potash JB, Zandi P, Lee RS. 2014. Alterations in DNA methylation of Fkbp5 as a determinant of blood-brain correlation of glucocorticoid exposure. Psychoneuroendocrinology 44: 112-122.

Fontanez-Nuin DE, Santini E, Quirk GJ, Porter JT. 2011. Memory for fear extinction requires mGluR5-mediated activation of infralimbic neurons. Cereb Cortex 21: 727-735.

Giustino TF, Maren S. 2015. The role of the medial prefrontal cortex in the conditioning and extinction of fear. Front Behav Neurosci 9: 298.

Gourley SL, Kedves AT, Olausson P, Taylor JR. 2009. A history of corticosterone exposure regulates fear extinction and cortical NR2B, GluR2/3, and BDNF. Neuropsychopharmacology 34: 707-716.

Gupta SC, Hillman BG, Prakash A, Ugale RR, Stairs DJ, Dravid SM. 2013. Effect of D-cycloserine in conjunction with fear extinction training on extracellular signal-regulated kinase activation in the medial prefrontal cortex and amygdala in rat. Eur J Neurosci 37: 1811-1822.

Hariri AR, Holmes A. 2015. Finding translation in stress research. Nat Neurosci 18: $1347-1352$

Hartmann J, Wagner KV, Gaali S, Kirschner A, Kozany C, Rühter G, Dedic N, Häusl AS, Hoeijmakers L, Westerholz S, et al. 2015. Pharmacological inhibition of the psychiatric risk factor FKBP51 has anxiolytic properties. J Neurosci 35: 9007-9016.

Hassani Z, Lemkine GF, Erbacher P, Palmier K, Alfama G, Giovannangeli C, Behr JP, Demeneix BA. 2005. Lipid-mediated siRNA delivery downregulates exogenous gene expression in the mouse brain at picomolar levels. J Gene Med 7: 198-207.

Herry C, Ciocchi S, Senn V, Demmou L, Muller C, Luthi A. 2008. Switching on and off fear by distinct neuronal circuits. Nature 454: 600-606.

Jin XC, Lu YF, Yang XF, Ma L, Li BM. 2007. Glucocorticoid receptors in the basolateral nucleus of amygdala are required for postreactivation reconsolidation of auditory fear memory. Eur J Neurosci 25: 3702-3712.

Kim JH, Li S, Richardson R. 2011. Immunohistochemical analyses of long-term extinction of conditioned fear in adolescent rats. Cereb Cortex 21: $530-538$

Koenen KC, Uddin M. 2010. FKBP5 polymorphisms modify the effects of childhood trauma. Neuropsychopharmacology 35: 1623-1624.

Li G, Amano T, Pare D, Nair SS. 2011. Impact of infralimbic inputs on intercalated amygdala neurons: a biophysical modeling study. Learn Mem 18: 226-240.

Matsumoto M, Yoshioka M, Togashi H. 2009. Early postnatal stress and neural circuit underlying emotional regulation. Int Rev Neurobiol 85: 95-107.

McKlveen JM, Myers B, Flak JN, Bundzikova J, Solomon MB, Seroogy KB, Herman JP. 2013. Role of prefrontal cortex glucocorticoid receptors in stress and emotion. Biol Psychiatry 74: 672-679.

Mehta D. 2011. Using polymorphisms in FKBP5 to define biologically distinct subtypes of posttraumatic stress disorder. Arch Gen Psychiatry 68: 901.

Milad MR, Quirk GJ. 2002. Neurons in medial prefrontal cortex signal memory for fear extinction. Nature 420: $70-74$.

Milad MR, Quirk GJ. 2012. Fear extinction as a model for translational neuroscience: ten years of progress. Annu Rev Psychol 63: 129-151.

Milad MR, Pitman RK, Ellis CB, Gold AL, Shin LM, Lasko NB, Zeidan MA, Handwerger K, Orr SP, Rauch SL. 2009. Neurobiological basis of failure to recall extinction memory in posttraumatic stress disorder. Biol Psychiatry 66: 1075-1082.

Morrison FG, Ressler KJ. 2014. From the neurobiology of extinction to improved clinical treatments. Depress Anxiety 31: 279-290.

Morrow BA, Elsworth JD, Inglis FM, Roth RH. 1999. An antisense oligonucleotide reverses the footshock-induced expression of fos in the rat medial prefrontal cortex and the subsequent expression of conditioned fear-induced immobility. J Neurosci 19: 5666-5673.

Mueller D, Porter JT, Quirk GJ. 2008. Noradrenergic signaling in infralimbic cortex increases cell excitability and strengthens memory for fear extinction. J Neurosci 28: 369-375.

Pattwell SS, Duhoux S, Hartley CA, Johnson DC, Jing D, Elliott MD, Ruberry EJ, Powers A, Mehta N, Yang RR. 2012. Altered fear learning across development in both mouse and human. Proc Natl Acad Sci 109: $16318-16323$

Peters J, Dieppa-Perea LM, Melendez LM, Quirk GJ. 2010. Induction of fear extinction with hippocampal-infralimbic BDNF. Science 328: $1288-1290$.
Quirk GJ, Mueller D. 2008. Neural mechanisms of extinction learning and retrieval. Neuropsychopharmacology 33: 56-72.

Quirk GJ, Likhtik E, Pelletier JG, Paré D. 2003. Stimulation of medial prefrontal cortex decreases the responsiveness of central amygdala output neurons. J Neurosci 23: 8800-8807.

Raio CM, Phelps EA. 2015. The influence of acute stress on the regulation of conditioned fear. Neurobiol Stress 1: 134-146.

Raubenheimer PJ, Young EA, Andrew R, Seckl JR. 2006. The role of corticosterone in human hypothalamic-pituitary-adrenal axis feedback. Clin Endocrinol (Oxf) 65: 22-26.

Revest J-M, Le Roux A, Roullot-Lacarrière V, Kaouane N, Vallée M, Kasanetz F, Rougé-Pont F, Tronche F, Desmedt A, Piazza PV. 2014. BDNF-TrkB signaling through Erk1/2 MAPK phosphorylation mediates the enhancement of fear memory induced by glucocorticoids. Mol Psychiatry 19: 1001-1009.

Rimmele U, Besedovsky L, Lange T, Born J. 2015. Emotional memory can be persistently weakened by suppressing cortisol during retrieval. Neurobiol Learn Mem 119: 102-107.

Rosenkranz JA, Venheim ER, Padival M. 2010. Chronic stress causes amygdala hyperexcitability in rodents. Biol Psychiatry 67: 1128-1136.

Santini E, Porter JT. 2010. M-type potassium channels modulate the intrinsic excitability of infralimbic neurons and regulate fear expression and extinction. J Neurosci 30: 12379-12386.

Santini E, Quirk GJ, Porter JT. 2008. Fear conditioning and extinction differentially modify the intrinsic excitability of infralimbic neurons. $J$ Neurosci 28: 4028-4036.

Santini E, Sepulveda-Orengo M, Porter JT. 2012. Muscarinic receptors modulate the intrinsic excitability of infralimbic neurons and consolidation of fear extinction. Neuropsychopharmacology 37: $2047-2056$

Sawamura T, Klengel T, Armario A, Jovanovic T, Norrholm SD, Ressler KJ, Andero R. 2015. Dexamethasone treatment leads to enhanced fear extinction and dynamic Fkbp5 regulation in amygdala. Neuropsychopharmacology 41: 832-846.

Scharf SH, Liebl C, Binder EB, Schmidt MV, Müller MB. 2011. Expression and regulation of the Fkbp5 gene in the adult mouse brain. PLoS One 6 e16883.

Sepulveda-Orengo MT, Lopez AV, Soler-Cedeno O, Porter JT. 2013. Fear extinction induces mGluR5-mediated synaptic and intrinsic plasticity in infralimbic neurons. J Neurosci 33: 7184-7193.

Sierra-Mercado D, Padilla-Coreano N, Quirk GJ. 2011. Dissociable roles of prelimbic and infralimbic cortices, ventral hippocampus, and basolateral amygdala in the expression and extinction of conditioned fear. Neuropsychopharmacology 36: 529-538.

Spijker AT, van Rossum EF. 2012. Glucocorticoid sensitivity in mood disorders. Neuroendocrinology 95: 179-186.

Tatro ET, Everall IP, Kaul M, Achim CL. 2009. Modulation of glucocorticoid receptor nuclear translocation in neurons by immunophilins FKBP51 and FKBP52: implications for major depressive disorder. Brain Res 1286: $1-12$.

Touma C, Gassen NC, Herrmann L, Cheung-Flynn J, Büll DR, Ionescu IA, Heinzmann J-M, Knapman A, Siebertz A, Depping A-M, et al. 2011. FK506 binding protein 5 shapes stress responsiveness: modulation of neuroendocrine reactivity and coping behavior. Biol Psychiatry 70: 928-936.

Van Zuiden M, Geuze E, Willemen HLDM, Vermetten E, Maas M, Amarouchi K, Kavelaars A, Heijnen CJ. 2012. Glucocorticoid receptor pathway components predict posttraumatic stress disorder symptom development: a prospective study. Biol Psychiatry 71: 309-316.

Van Zuiden M, Kavelaars A, Geuze E, Olff M, Heijnen CJ. 2013. Predicting PTSD: pre-existing vulnerabilities in glucocorticoid-signaling and implications for preventive interventions. Brain Behav Immun 30: $12-21$.

Vedeckis WV, Ali M, Allen HR. 1989. Regulation of glucocorticoid receptor protein and mRNA levels. Cancer Res 49: 2295s-2302s.

Vidal-Gonzalez I, Vidal-Gonzalez B, Rauch SL, Quirk GJ. 2006 Microstimulation reveals opposing influences of prelimbic and infralimbic cortex on the expression of conditioned fear. Learn Mem 13: $728-733$.

Wessa M, Flor H. 2007. Failure of extinction of fear responses in posttraumatic stress disorder: evidence from second-order conditioning. Am J Psychiatry 164: 1684-1692.

Xie P, Kranzler HR, Poling J, Stein MB, Anton RF. 2010. Interaction of FKBP5 with childhood adversity on risk for post-traumatic stress disorder. Neuropsychopharmacology 35: 1684-1692.

Yehuda R, LeDoux J. 2007. Response variation following trauma: a translational neuroscience approach to understanding PTSD. Neuron 56: $19-32$.

Received May 19, 2016; accepted in revised form January 17, 2017. 


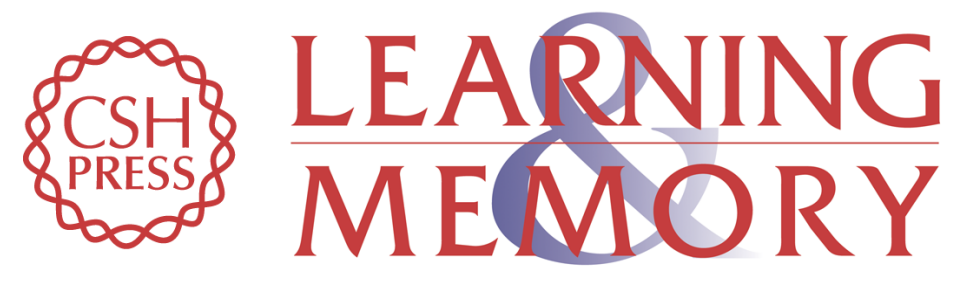

\section{Dynamic expression of FKBP5 in the medial prefrontal cortex regulates resiliency to conditioned fear}

Marangelie Criado-Marrero, Roberto J. Morales Silva, Bethzaly Velazquez, et al.

Learn. Mem. 2017, 24:

Access the most recent version at doi:10.1101/Im.043000.116

References This article cites 62 articles, 15 of which can be accessed free at: http://learnmem.cshlp.org/content/24/4/145.full.html\#ref-list-1

Creative This article is distributed exclusively by Cold Spring Harbor Laboratory Press for the Commons License first 12 months after the full-issue publication date (see

http://learnmem.cshlp.org/site/misc/terms.xhtml). After 12 months, it is available under a Creative Commons License (Attribution-NonCommercial 4.0 International), as described at http://creativecommons.org/licenses/by-nc/4.0/.

Email Alerting Receive free email alerts when new articles cite this article - sign up in the box at the Service top right corner of the article or click here. 